\title{
Faktor Keberhasilan dan Kegagalan Implementasi ERP-SAP Pada Industri Retail di Indonesia
}

\author{
Eko Hardi Suryantoro \\ Universitas Respati Indonesia \\ E-mail : ekohardis60@gmail.com
}

\begin{abstract}
Abstrak
SAP sebagai salah satu produk ERP terbaik saat ini telah dilengkapi dengan solusi praktek bisnis terbaik dikelasnya. Berdasarkan pengalaman yang panjang, adanya kegagalan pada saat implementasi SAP bukan semata dikarenakan produk solusi. Hal ini lebih dikarenakan pada pelbagai faktor yang terkait ketika melakukan implementasi. Penelitian ini membuktikan adanya faktor yang mempengaruhi keberhasilan dan kegagalan implementasi SAP. Penelitian dilakukan pada ranah industri retail di Indonesia. Dilakukan analisa berdasar pemodelan teori akseptasi tehnologi, pemodelan keberhasilan DeLone dan mengacu pada kerangka kerja manajemen proyek PMBOK. Hipotesis ditegakan berdasarkan analisa regresi linier dan pemodelan SEM. Beberapa faktor diketahui menjadi penyebab keberhasilan dan kegagalan implementasi SAP pada industri di retail di Indonesia terungkap. Antara lain : kualitas keluaran, relevansi pekerjaan, pandangan pengguna sistem, hasil yang dapat ditunjukan, kompatibilitas, kehandalan sistem, kapabilitas menghasilkan keluaran, dukungan internal/eksternal, partisipasi pengguna, dan manajemen proyek sistem informasi.
\end{abstract}

Kata Kunci : SAP, faktor keberhasilan dan kegagalan,industri retail di Indonesia

\begin{abstract}
SAP as one of the best ERP products today is equipped with best-in-class business practice solutions. Based on long experience, a failure during SAP implementation was not solely due to the product solution. This is more due to the various factors involved when implementing it. This study proves that there are factors that influence the success and failure of SAP implementation. The research was conducted in the realm of the retail industry in Indonesia. Analyzes were conducted based on technological acceptance theory modeling, DeLone success modeling and referring to the PMBOK project management framework. The hypothesis was established based on linear regression analysis and SEM modeling. Several factors are known to be the cause of the success and failure of SAP implementation in the retail industry in Indonesia. Among others: output quality, job relevance, system user views, results that can be demonstrated, compatibility, system reliability, output capability, internal / external support, user participation, and information system project management.
\end{abstract}

Keywords: SAP, success and failure factors, retail industry in Indonesia 


\section{PENDAHULUAN}

Faktor Kritis Keberhasilan (Critical Success Factor/CSF's) pada implementasi ERP telah banyak dibahas pada berbagai kajian literatur. Pada penelitian tersebut telah di identifikasi faktor keberhasilan ketika pada tahap seleksi solusi dan prosedur kritis implementasi agar implementasi berhasil.[1] [9]

Implementasi ERP pada industri retail juga akan menemui hal yang sama. Setidaknya ada 6 faktor yang mengindikasi keberhasilan implementasi ERP. [22]. Telah diketahui bahwa adanya kesenjangan kultur dan ketidak-siapan perusahaan merupakan faktor terpenting yang menjadikan penyumbang utama kegagalan implementasi ERP pada 15 perusahaan [2][7][10]. Hampir $80 \%$ dari perusahaan berskala enterprise di Indonesia telah mengimplementasikan SAP. Setidaknya ada 5 jenis industri, antara lain : Jasa profesional 13\%, Pelayanan pelanggan $11 \%$, Distributor $10 \%$, Furniture $7 \%$ dan industri Retail 6\%. Sementara itu APRINDO Asosiasi Retail Indonesia menyatakan bahwa bisnis industri retail di Indonesia tumbuh sekitar $7.5 \%$ pertahunya, dengan pemain industri retail sebanyak 150 . Memahami pentingnya dalam mengetahui faktor keberhasilan dan kegagalan implementasi pada industri retail di Indonesia menjadi hal yang sangat krusial. Hal ini terkait dengan besarnya biaya implementasi SAP dan dampaknya secara masive. Solusi SAP retail itu sendiri pada giliranya mampu menjadi game-changing experience terhadap perusahaan dan kebutuhan pelanggan.[3][8]

Solusi SAP pada industri retail "IS Retail (ISR) Solution" merupakan spesifik solusi SAP yang dirancang untuk membantu industri retail dalam menjalankan bisnis. Merupakan solusi komprehensif dan terintegrasi. Dioperasikan untuk skala enterprise. Solusi ini dapat dipetakan bagi seluruh skenario bisnis retail, proses bisnis dan fungsi bisnis. Solusi ini dapat membantu pada fungsi bisnis : pemasaran, pengadaan, pembeliaan, rantai pasokan, manajemen gudang, operasional toko hingga manajemen akuntasi dan keuangan. [3][1]

Solusi retail dilengkapi dengan integrasi untuk seluruh bagian dan fungsi bisnis dalam industri retail, baik untuk jenis sektor restauran, pakaian, hingga departemen store. Solusinya sangat customizeable dalam memenuhi kebutuhan proses bisnis.[15].

http://ejournal.urindo.ac.id/index.php/TI
Produk flagship SAP yakni ECC 6.0 (Enterprise Central Component Version 6.0) merupakan solusi yang telah siap dihadirkan pada industri retail. Solusi ini dilengkapi dengan 3 modul inti terkait dengan bisnis organisasi [12][13].

- Keuangan/Kontrol

- Logistik

- Sumber Daya Manusia

Modul logistik mempunyai submodul Manajemen Material (MM), Penjualan \& Distribusi (SD), Perencanaan Produksi (PP), Manajamen Pabrik (PM), Manajemen Mutu (QM), dan Manajemen Gudang (WM) [19][21]. Solusi SAP untuk industri retail merupakan komponen yang tidak terpisahkan dari modul induk ECC. Fungsi utama dari retail yang ditambahkan untuk industri retail disebut sebagai Retail Component[3][4] antara lain :

1. Perencanaan Pengisian Barang

2. Manajemen Pemilihan Barang

3. Promosi

4. Manajemen Harga

5. Manajemen Barang.

Secara garis besar model SAP IS Retail adalah : [20]

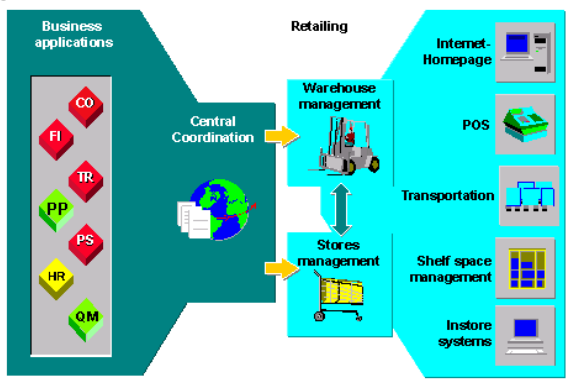

Gambar 1 : SAP IS Retail

Suatu proyek menurut PMBOK, adalah kegiatan sementara, yang mempunyai titik awal dan akhir dalam waktu, oleh karenanya harus ditentukan cakupan dan sumber dayanya. Suatu proyek harus unik yang bukan merupakan kegiatan operasi rutin, tetapi kegiatan spesifik yang dirancang untuk mencapai suatu tujuan. Manajemen proyek dibagi dalam 5 proses : Inisiasi, Perencanaan, Eksekusi, Pemantauan dan Pengawasan, Penutupan. Manajemen proyek melingkupi 10 area pengetahuan manajemen proyek : Integrasi, Cakupan, 
Waktu, Biaya, Kualitas, Pengadaaan, SDM,Komunikasi, Manajemen Resiko, Manajemen Pemangku Kebijakan. Seluruh manajamen perusahaan akan memberikan perhatian khusus terhadap hal ini. Namun manajemen proyek harus lebih fokus secara pada tujuan pencapaian, sumber daya dan jadual proyek.[4]

Implementasi ERP bukan merupakan hal yang mudah dan berbeda dengan proyek Tehnologi Informasi (TI) lainya, karena terkait daur ulang proses bisnis dan optimalisasi. Manajemen proyek ERP tidak sama dengan implementasi sistem TI skala kecil. Harus memperhatikan secara khusus pada aspek implementasi meliputi : membangun inisiasi kasus bisnis dan perencanaan proyek, konfigurasi dan implementasi solusi, termasuk melakukan perbaikan proses bisnis. Seluruh pemasok ERP telah mengetahui metodologi implementasi terhadap produk ERP mereka. ASAP dan AIM merupakan salah satu metodologi yang saat ini digunakan SAP dan ORACLE. Kedua perusahaan ini menerapkan standardisasi tersendiri dalam implementasi ERP guna mempercepat proses implementasi. Kedua metodologi ini tetap mengacu pada PMBOK. Dengan metodologi ini memungkinkan pelanggan untuk menggunakan cara sama yang telah dilakukan oleh ribuan perusahaan.[18]. Metodologi SAPSAP terdiri dari tahapan sebagai berikut : Persiapan Proyek - Cetak Biru Bisnis - Realisasi - Persiapan Akhir Go Live dan Support. Lebih jauh lagi pada berbagai jurnal disebutkan berbagai metodologi implementasi jenis lainya. Metodologi SAP ASAP implementasi seperti terlihat paga gambar dibawah. [5]

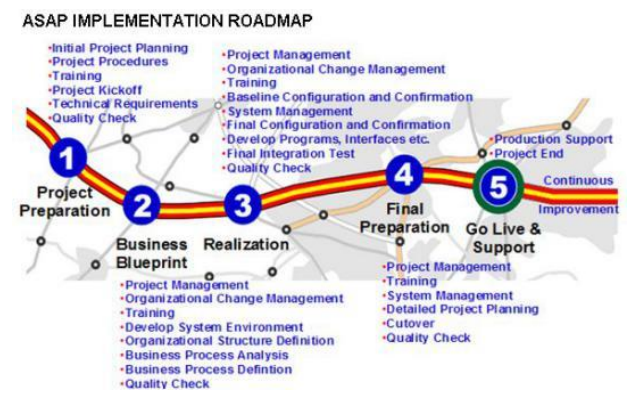

Gambar 2: Metodologi SAP ASAP

\section{A. Model Akseptasi Tehnologi - TAM (Technology}

Acceptance Model) and DeLone McLean Models

Berbagai model teori telah bermunculan untuk mendalami dan menjelaskan faktor-faktor yang http://ejournal.urindo.ac.id/index.php/TI menyebabkan penguna untuk menerima, menolak atau tetap melanjutkan penggunaan tehnologi baru [23]. Berawal dari penelitian model Ajzen dan Fishbein, Teori Aksi Reaksi (TRA) menghadirkan perkembangan teori TAM, dan dilengkapi dengan teori konteks yang dapat menjelaskan hubungan antara sikap-niat-tingkah. TAM secara empiris terdukung untuk menjadi komprehensif dalam melakukan prediksi akseptansi tehnologi dan adopsi.TAM menjelaskan bahwa kinerja tingkah laku individu ditentukan oleh niat tingkah lakunya dalam melakukan kegiatan tersebut. Hal ini merupakan variabel spesifik, yang dapat ditarik kesimpulan menjadi faktor determinan penerimaan individu. Model dan jumlah variabel dapat dilihat pada gambar dibawah : [6]

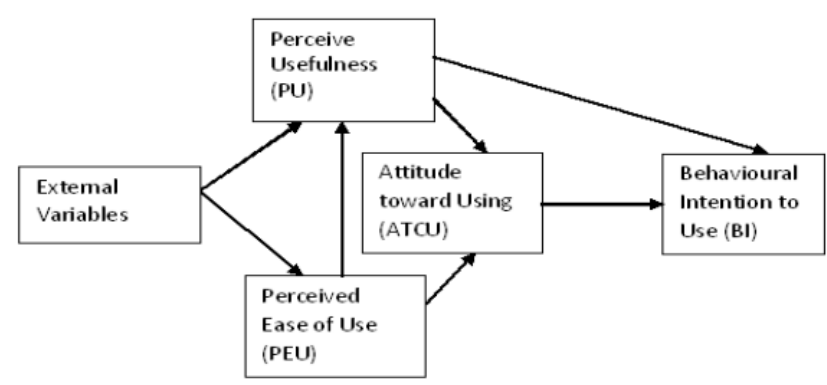

Gambar 3 : Model Akseptasi Tehnologi (TAM)

Pada model DeLone-McLean yang diperbaharui, niat tingkah laku di ekspresikan oleh variabel niat yang merupakan anticedent dari niat untuk tidak menggunakan. Niat untuk menggunakan diawali dengan adanya informasi yang berkualitas, sistem yang berkualitas dan layanan yang berkualitas [16]. Ketika variabel yang disebutkan berasal dari aspek tehnis sistem informasi, sementara niat untuk menggunakan di ilhami oleh teori psikologi. Beberapa penelitian berfokus memahami variabel niat untuk menggunaan. Kebanyakan penelitian dilaksanakan pada penelitian terkait akseptansi tehnologi. Ditunjukan bahwa disamping memberikan dampak bagi kualitas informasi, kualitas sistem, kualitas pelayanan dan kepuasan pengguna, maka niat untuk mengunakan juga berdampak pada variabel lainya antara lain : anggapan ketidak manfaatan dan anggapan mudah dalam penggunaan.[24]. Kedua variabel sudah umum dipergunakan dan telah terbukti menjadi lawan dari tingkah laku niat pada penelitian akseptansi tehnologi. Meskipun DeLone dan McLean menyarankan bahwa penggunaan sistem merupakan variabel yang sangat 
penting dalam mengukur keberhasilan penggunaan sistem informasi, kenyataanya niat untuk menggunakan juga menjadi bagian penting dari keberhasilan sistem, karena secara psikologis pengguna tidak akan menggunakan sistem jika memang mereka tidak berkehendak. Teori psikologi menggaris bawahi bahwa asumsi ini dibangun atas dasar teori aksi reaksi (TRA) [17]. Pada TRA ,niat individu utuk bertindak dalam beberapa hal akan memberikan manfaat bagi dirinya dan akan mendapat dukungan individu lainya, jika mereka melihat manfaatnya. Model secara lengkap dapat dilihat pada gambar dibawah :[6]

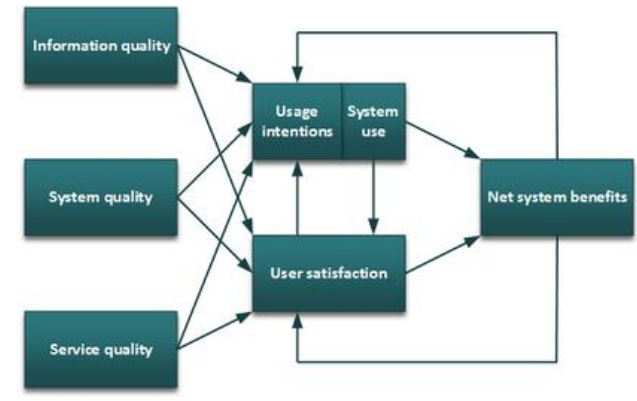

Gambar 4 : Model DeLone dan McLane

METODE

Penelitian menggunakan model kuantitatif yang direpresentasikan dengan model statistik guna menganalisa variabel terkait. Sumber data primer diambil dari kuestioner dan wawancara langsung dengan profesional dibidangnya. Populasi sampling diambil dari industri retail di pelbagai sektor antara lain : resturan, departemen store, toko konsep tunggal, fashion, sports, toko buku, grocerie, dan supermaket. Setidaknya sekitar 40 perusahaan retail yang dilakukan survei dan melibatkan lebih dari 200 penguna sistem dan sebagian fungsi bisnis. Berikut adalah komposisi responden.

\begin{tabular}{|c|r|r|r|r|}
\hline Departmen & \multicolumn{1}{|c|}{$\begin{array}{c}\text { \% } \\
\text { Dept. }\end{array}$} & $\begin{array}{c}\text { \# of } \\
\text { Pengguna }\end{array}$ & $\begin{array}{c}\text { \# SAP } \\
\text { Pengguna }\end{array}$ & $\begin{array}{c}\text { Total } \\
\text { Penguna }\end{array}$ \\
\hline Akunting & 5 & 10 & 40 & 400 \\
\hline Keuangan & 10 & 20 & 40 & 800 \\
\hline
\end{tabular}

http://ejournal.urindo.ac.id/index.php/TI

\begin{tabular}{|c|r|r|r|r|}
\hline Administrasi & 5 & 10 & 40 & 400 \\
\hline Inventori & 5 & 10 & 40 & 400 \\
\hline SDM & 5 & 10 & 40 & 400 \\
\hline MIS/IT & 5 & 10 & 40 & 400 \\
\hline Pengadaan & 30 & 60 & 40 & 2400 \\
\hline Pembeliaan & 10 & 20 & 40 & 800 \\
\hline Gudang & 10 & 20 & 40 & 800 \\
\hline Toko & 10 & 20 & 40 & 800 \\
\hline Pengiriman & 5 & 10 & 40 & 400 \\
\hline Total & $\mathbf{1 0 0}$ & $\mathbf{2 0 0}$ & & $\mathbf{8 0 0 0}$ \\
\hline
\end{tabular}

\section{Tabel 1 : Komposisi Responden Survei}

Data diambil berdasarkan model sampling proporsional menggunakan kuestioner skala "Likert" dibawah ini:

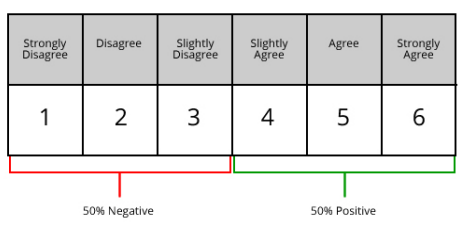

Tabel 1: Skala Likert

\section{B. Kerangka Penelitian}

Data primer berasal dari responden pada perusahaan retail yang telah melakukan implementasi SAP. Data tersebut dianalisa menggunakan tiga model pendekatan akseptansi dan manajemen proyek. Ketiga pendekatan model tersebut adalah : Model Akseptansi tehnologi menggunakan TAM untuk mengukur tingkat kepuasan penggunaan SAP, Model DeLone dan McLane untuk mengukur keberhasilan implementasi sistem informasi dan manajemen proyek PMBOK dan SAP ASAP untuk mengukur keberhasilan implementasi proyek. Variabel untuk selanjutnya diuji menggunakan teori regresi dan pemodelan SEM guna melihat pengaruh dan tingkat dependensi pada masing-masing variabel. Model kerangka penelitian sebagai mana dibawah ini : 


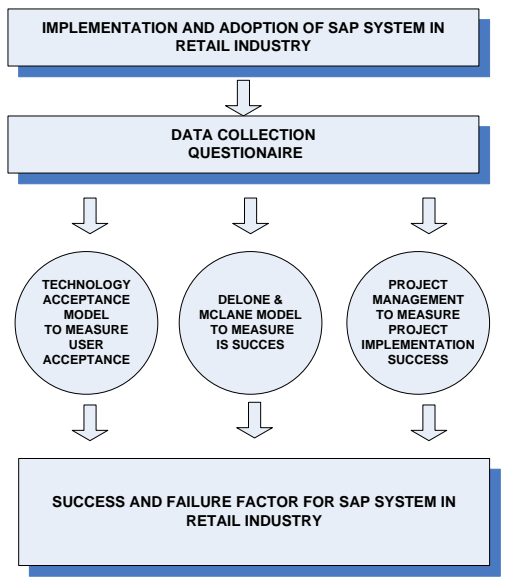

Gambar 5: Model Kerangka Penelitian

\section{Struktur Penelitian}

Model struktur penelitian menggunakan kombinasi model akseptansi tehnologi (TAM), Mode1 DeLone \& McLane (DM) dan manajemen proyek. Setidaknya 22 variabel terkait dengan penelitian ini di ukur. Antara lain : kualitas pekerjaan, relevansi pekerjaan, tanggapan pengguna, hasil yang dapat dilihat, kompatibilitas, tingkat reliabiliti sistem, kapabilitas sistem, dukungan internal, dukungan konsultan, info partisipasi, norma subyektivitas, anggapan ketidak manfaatan, kepuasan pengguna, kemudahan penggunaan, niat untuk menggunakan, keberhasilan proyek, dampak terhadap individu dan organisasi. Struktur model penelitian sebagaimana terlihat gambar dibawah :

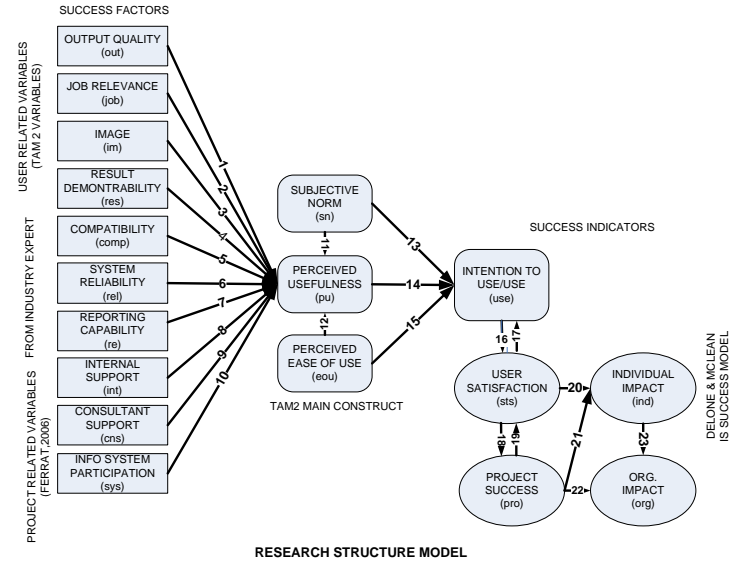

Gambar 6 : Struktur Model Penelitian

\section{Faktor Keberhasilan/Kegagalan}

Setidaknya ada 7 variabel yang diuji untuk menegakan diagnosa penelian berdasar teori TAM :

1. Kualitas Keluaran : Menentukan apakah sistem mampu melakukan tugas yang dikehendaki.

2. Relevansi Pekerjaan : Komponen kunci guna mengukur apakah sistem terkait dengan pekerjaan

3. Anggapan : Persepektif pengguna secara umum apakah sistem telah memberikan dampak bagus/buruk.

4. Hasil yang dapat dilihat : Sistem harus mampu memberikan hasil ekspektasi yang diharapkan dengan hasil yang akurat.

5. Kompatibilitas : Menguji apakah inovasi mampu menerima pertukaran informasi dengan sistem lain

6. Reliabilitas Sistem : Tingkat kepercayaan pengguna sistem dalam menerima sistem

7. Kapabilitas Laporan : Kapabilitas sistem untuk menghasilkan laporan yang akurat.

8. Dukungan Internal : Seberapa jauh dukungan implementasi dari team internal.

9. Dukungan Konsultan : Seberapa jauh dukungan dari konsultan

10. Tingkat Partisipasi : Seberapa jauh sistem mampu membantu organisasi. 
Variabel lain juga di uji guna mengukur keberhasilan/kegagalan implementasi SAP pada organisasi.

1. Norma Subyektivitas : Norma Subyektivitas pengguna

2. Manfaat : Tingkat akseptansi manfaat

3. Kemudahan Penggunaan : Tingkat kemudahan

4. Niat penggunaan : Siapa yang akan menggunakan sistem.

5. Kepuasan Pengguna : Tingkat kepuasan pengguna sistem

6. Keberhasilan Proyek : Mengukur keberhasilan implementasi proyek.

7. Dampak Individu : Dampak bagi individu ketika mengakses sistem

8. Dampak Organisasi : Dampak implementasi sistem bagi organisasi

HASIL

Data primer diambil dari survei yang dilakukan selama 4 bulan dengan melibatkan responden pengguna SAP IS Retail pada industri retail. Pengguna dapat diklasifikasikan :

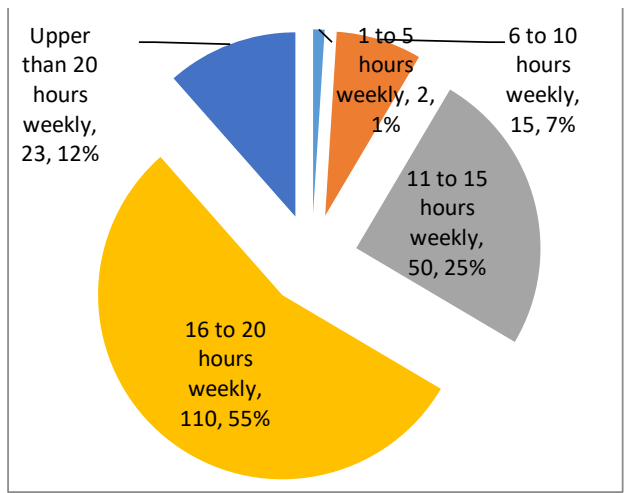

Berdasar fungsi bisnis, pengguna terbesar adalah Merchandiding, sebesar $84 \%$

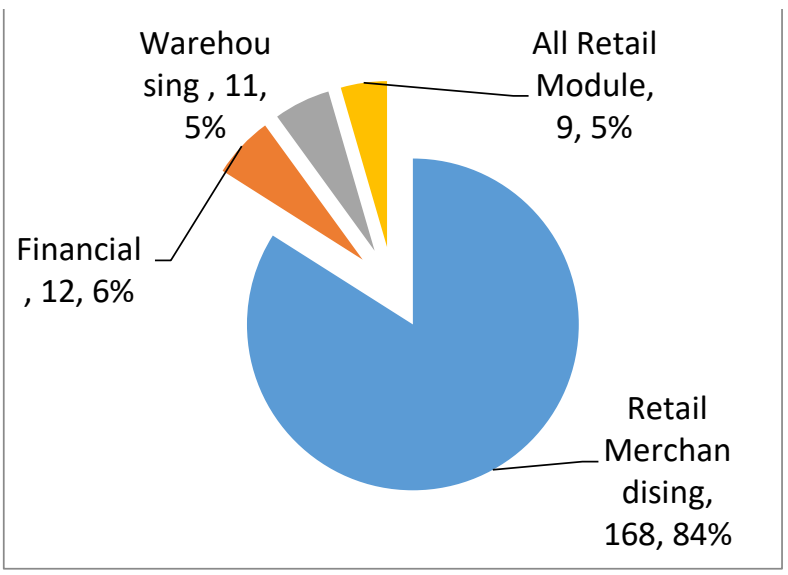

Industri retail di Indonesia berdasar jenis model bisnisnya terbagi dalam :

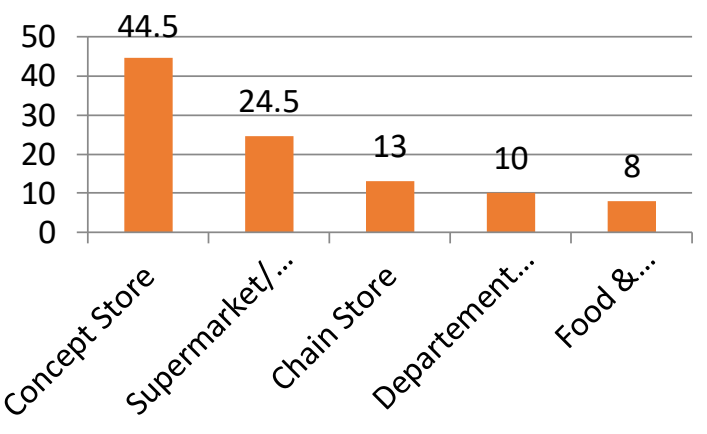

VALIDITAS

Konstruksi validitas ditegakan dalam penelitian ini. Model pengujian yang populer adalah sebagai berikut :

$$
r_{x y}=\frac{n\left(\sum X Y\right)-\left(\sum X\right)\left(\sum Y\right)}{\sqrt{\left[n\left(\sum X^{2}\right)-\left(\sum X\right)^{2} \mid n\left(\sum Y^{2}\right)-\left(\sum Y\right)^{2}\right]}}
$$

Dimana :

- Rxy = Korelasi Koefisien Variabel

- $\mathrm{n}=$ Jumlah Obyek Penelitian

$-\mathrm{X}=$ Jumlah nilai

$-Y=$ Total nilai

Nilai "r" divalidasi menggunakan rtabel atau menggunakan standard nilai validitas : "0.3". Jika variabel "rcount" > "rtabel" atau "0.3" menunjukan bahwa variabel tersebut valid. Berikut tabel hasil perhitunganya : 


\begin{tabular}{|c|c|c|c|}
\hline Pertanyaan & R.Table & R.Hitung & Hasil \\
\hline P1 & 0.685 & 0.3 & Valid \\
\hline P2 & 0.613 & 0.3 & Valid \\
\hline P3 & 0.461 & 0.3 & Valid \\
\hline P4 & 0.639 & 0.3 & Valid \\
\hline P5 & 0.635 & 0.3 & Valid \\
\hline P6 & 0.591 & 0.3 & Valid \\
\hline P7 & 0.517 & 0.3 & Valid \\
\hline P8 & 0.618 & 0.3 & Valid \\
\hline P9 & 0.637 & 0.3 & Valid \\
\hline P10 & 0.618 & 0.3 & Valid \\
\hline P11 & 0.629 & 0.3 & Valid \\
\hline P12 & 0.438 & 0.3 & Valid \\
\hline P13 & 0.675 & 0.3 & Valid \\
\hline P14 & 0.643 & 0.3 & Valid \\
\hline P15 & 0.614 & 0.3 & Valid \\
\hline P16 & 0.748 & 0.3 & Valid \\
\hline P17 & 0.471 & 0.3 & Valid \\
\hline $\begin{array}{l}\text { P18 } \\
\text {. }\end{array}$ & 0.677 & 0.3 & Valid \\
\hline P19 & 0.537 & 0.3 & Valid \\
\hline $\mathrm{P} 20$ & 0.699 & 0.3 & Valid \\
\hline $\mathrm{P} 21$ & 0.649 & 0.3 & Valid \\
\hline P22 & 0.593 & 0.3 & Valid \\
\hline $\mathrm{P} 23$ & 0.579 & 0.3 & Valid \\
\hline P24 & 0.814 & 0.3 & Valid \\
\hline P25 & 0.702 & 0.3 & Valid \\
\hline P26 & 0.678 & 0.3 & Valid \\
\hline P27 & 0.616 & 0.3 & Valid \\
\hline P28 & 0.810 & 0.3 & Valid \\
\hline P29 & 0.809 & 0.3 & Valid \\
\hline P30 & 0.822 & 0.3 & Valid \\
\hline P31 & 0.679 & 0.3 & Valid \\
\hline P32 & 0.801 & 0.3 & Valid \\
\hline
\end{tabular}

\begin{tabular}{|c|c|c|c|}
\hline P33 & 0.627 & 0.3 & Valid \\
\hline P34 & 0.668 & 0.3 & Valid \\
\hline P35 & 0.565 & 0.3 & Valid \\
\hline P36 & 0.809 & 0.3 & Valid \\
\hline P37 & 0.761 & 0.3 & Valid \\
\hline P38 & 0.775 & 0.3 & Valid \\
\hline P39 & 0.686 & 0.3 & Valid \\
\hline $\mathrm{P} 40$ & 0.559 & 0.3 & Valid \\
\hline P41 & 0.667 & 0.3 & Valid \\
\hline P42 & 0.704 & 0.3 & Valid \\
\hline $\mathrm{P} 43$ & 0.466 & 0.3 & Valid \\
\hline P44 & 0.831 & 0.3 & Valid \\
\hline P45 & 0.767 & 0.3 & Valid \\
\hline P46 & 0.690 & 0.3 & Valid \\
\hline P47 & 0.758 & 0.3 & Valid \\
\hline $\mathrm{P} 48$ & 0.649 & 0.3 & Valid \\
\hline $\mathrm{P} 49$ & 0.712 & 0.3 & Valid \\
\hline P50 & 0.715 & 0.3 & Valid \\
\hline P51 & 0.750 & 0.3 & Valid \\
\hline P52 & 0.662 & 0.3 & Valid \\
\hline P53 & 0.726 & 0.3 & Valid \\
\hline P54 & 0.670 & 0.3 & Valid \\
\hline P55 & 0.680 & 0.3 & Valid \\
\hline P56 & 0.336 & 0.3 & Valid \\
\hline P57 & 0.411 & 0.3 & Valid \\
\hline P58 & 0.308 & 0.3 & Valid \\
\hline P59 & 0.445 & 0.3 & Valid \\
\hline P60 & 0.482 & 0.3 & Valid \\
\hline P61 & 0.484 & 0.3 & Valid \\
\hline
\end{tabular}

\section{RELIABILITAS}

Guna menguji konsistensi, penelitian ini menggunakan model alpha cronback dengan rumus sebagai berikut : 


$$
r_{11}=\left[\frac{k}{k-1}\right]\left[1-\frac{\sum \sigma_{b}^{2}}{V_{t}^{2}}\right] \text { (Arikunto, 1999,193) }
$$

Dimana :

r.11 $=$ instrumen reliabilitas

$\mathrm{k}=$ Jumlah pertanyaan

$\sum \sigma_{b}^{2}=$ Jumlah varian per items

$V_{t}^{2}=$ total varian

Kriteria instrumen dapat dianggap dipercaya jika koefisien reliabilitas $r 11>0.6$.

\begin{tabular}{|c|c|c|c|}
\hline Variabel & R.Tabel & R.Hitung & Remark \\
\hline Variabel X1 & 0.873 & 0.6 & Reliabel \\
\hline Variabel X2 & 0.840 & 0.6 & Reliabel \\
\hline Variabel X3 & 0.899 & 0.6 & Reliabel \\
\hline Variabel Y & 0.935 & 0.6 & Reliabel \\
\hline Variabel Z & 0.929 & 0.6 & Reliabel \\
\hline
\end{tabular}

\section{TES HIPOTESIS DAN ANALISA REGRESI}

Guna melakukan pengujian konsistensi dengan multi variabel , maka harus menggunakan analisa tes multi regresi. Uji hipotesa dengan menganalisa signifikasi pemberatan regresi guna mengukur dampak variabel secara langsung atau tidak langsung. Uji regresi akan signifikan :

1. Jika nilai $\mathrm{p}<$ alpha 0,005 hipotesis menjadi 0 dan Ho ditolak. Maknanya ada dampak diantara kedua variabel secara statistik.

2. Jika nilai $\mathrm{p}>$ alpha 0,005 hipotesis menjadi 0 dan Ho diterima. Maknanya tidak ada dampak diantara kedua variabel secara statistik.. 


\begin{tabular}{|c|c|c|c|c|c|}
\hline Alur & $\begin{array}{r}U j \\
i k e \#\end{array}$ & $\begin{array}{c}\text { Beta } \\
\text { tidak } \\
\text { standard }\end{array}$ & $\begin{array}{r}\text { Sta } \\
\text { ndard } \\
\text { Beta }\end{array}$ & $\underset{P}{\text { ilai }^{N}}$ & Hasil \\
\hline${ }_{\mathrm{PU}}$ OUT $\rightarrow$ & 1 & 0.092 & $6^{0.13}$ & $.000^{0}$ & Signifikan \\
\hline${ }_{\mathrm{PU}}{ }^{\mathrm{JOB}} \rightarrow$ & 2 & 0.093 & $6 \quad 0.13$ & $.000^{0}$ & Signifikan \\
\hline${ }_{\mathrm{PU}}{ }^{\mathrm{IM}} \rightarrow$ & 3 & 0.073 & $0 \quad 0.13$ & $.000^{0}$ & Signifikan \\
\hline $\begin{array}{ll}\mathrm{PU} & \mathrm{RES}\end{array}$ & 4 & -0.125 & $\begin{array}{r}- \\
0.178\end{array}$ & $.000^{0}$ & Signifikan \\
\hline $\begin{array}{l}\text { COMP } \\
\rightarrow \text { PU }\end{array}$ & 5 & 0.041 & $\begin{array}{ll} & 0.05 \\
5 & \end{array}$ & $.164^{0}$ & Signifikan \\
\hline${ }_{\mathrm{PU}}{ }^{\mathrm{REL}} \rightarrow$ & 6 & 0.147 & $\begin{array}{ll} & 0.21 \\
7 & \end{array}$ & $.000^{0}$ & Signifikan \\
\hline${ }_{\mathrm{PU}}{ }^{\mathrm{RE}} \rightarrow$ & 7 & -0.164 & 0.227 & $.000^{0}$ & Signifikan \\
\hline${ }_{\mathrm{PU}}{ }^{\mathrm{INT}} \rightarrow$ & 8 & 0.272 & $\begin{array}{ll} & 0.29 \\
1 & \end{array}$ & $.000^{0}$ & Signifikan \\
\hline${ }_{\mathrm{PU}} \mathrm{CNS} \rightarrow$ & 9 & -0.251 & $\begin{array}{r}- \\
0.335\end{array}$ & $.000^{0}$ & Signifikan \\
\hline${ }_{\mathrm{PU}} \mathrm{SYS} \rightarrow$ & 10 & 0.113 & $\begin{array}{ll} & 0.14 \\
3 & \end{array}$ & $.000^{0}$ & Signifikan \\
\hline${ }_{\mathrm{PU}} \mathrm{SN} \rightarrow$ & 11 & 0.396 & $\begin{array}{ll} & 0.48 \\
2 & \end{array}$ & $.000^{0}$ & Signifikan \\
\hline${ }_{\mathrm{PU}} \mathrm{EOU} \rightarrow$ & 12 & -0.077 & 0.105 & $.008^{0}$ & Signifikan \\
\hline$\underset{\mathrm{USE}}{\mathrm{SN}} \rightarrow$ & 13 & 0.966 & $\begin{array}{ll} & 1.29 \\
8 & \end{array}$ & $.000^{0}$ & Signifikan \\
\hline $\begin{array}{ll}\text { USE } & \text { PU }\end{array}$ & 14 & 0.381 & $0 \quad 0.42$ & $.000^{0}$ & Signifikan \\
\hline$\underset{\mathrm{USE}}{\mathrm{EOU}} \rightarrow$ & 15 & 0.685 & $\begin{array}{ll} & 1.02 \\
8 & \end{array}$ & $.000^{0}$ & Signifikan \\
\hline$\underset{\text { STS }}{\text { USE } \rightarrow}$ & 16 & 1.538 & 1.46 & $.000^{0}$ & Signifikan \\
\hline$\underset{\text { USE }}{\text { STS }} \rightarrow$ & 17 & -1.390 & 1.461 & $.000^{0}$ & Signifikan \\
\hline $\begin{array}{l}\text { STS } \rightarrow \\
\text { PRO }\end{array}$ & 18 & 0.752 & $\begin{array}{ll} & 0.62 \\
8 & \end{array}$ & $\begin{array}{l}0 \\
.000^{0}\end{array}$ & Signifikan \\
\hline$\underset{\text { STS }}{\operatorname{PRO} \rightarrow}$ & 19 & -.358 & 0.429 & $.009^{0}$ & Signifikan \\
\hline $\begin{array}{l}\text { STS } \rightarrow \\
\text { IND }\end{array}$ & 20 & 0.793 & $\begin{array}{ll} & 0.73 \\
7 & \end{array}$ & $\begin{array}{c}0 \\
.000^{0}\end{array}$ & Signifikan \\
\hline $\begin{array}{l}\text { PRO } \rightarrow \\
\text { IND }\end{array}$ & 21 & 0.061 & $\begin{array}{ll} & 0.06 \\
8 & \end{array}$ & $.202^{0}$ & $\begin{array}{c}\text { Tidak } \\
\text { Signifikan }\end{array}$ \\
\hline $\begin{array}{l}\text { PRO } \rightarrow \\
\text { ORG }\end{array}$ & 22 & 0.406 & $\begin{array}{ll} & 0.33 \\
5 & \end{array}$ & $.000^{0}$ & Signifikan \\
\hline $\begin{array}{ll}\text { IND } & \rightarrow \\
\text { ORG } & \end{array}$ & 23 & 0.744 & $\begin{array}{ll} & 0.55 \\
2 & \end{array}$ & $.000^{0}$ & Signifikan \\
\hline
\end{tabular}

Berdasar tabel model regresi dapat disimpulkan :
3. nHipotesis Kualitas Keluaran: Hasil menunjukan ada dampak antara kualitas produk terhadap keberhasilan/kegagalan implementasi SAP

4. Hipotesis Relevansi : Hasil menunjukan bahwa ada dampak antara profesi staff terhadap keberhasilan/kegagalan pada implementasi SAP

5. Hipotesis Anggapan : Hasil menunjukan bahwa ada dampak antara hasil anggapan terhadap keberhasilan/kegagalan pada implementasi SAP

6. Hipotesis Hasil Sistem : Hasil menunjukan bahwa ada dampak antara hasil sistem terhadap keberhasilan/kegagalan pada implementasi SAP

7. Hipotesis Komtabilitas : Hasil menunjukan bahwa ada dampak antara hasil komtabilitas terhadap keberhasilan/kegagalan pada implementasi SAP

8. Hipotesis reliabilitas sistem : Hasil menunjukan bahwa ada dampak antara reliabilitas sistem terhadap keberhasilan/kegagalan pada implementasi SAP

9. Hipotesis Kapabilitas Keluaran : Hasil menunjukan bahwa ada dampak antara kapabilitas keluaran terhadap keberhasilan/kegagalan pada implementasi SAP

10. Hipotesis Dukungan Internal : Hasil menunjukan bahwa ada dampak antara dukungan internal terhadap keberhasilan/kegagalan pada implementasi SAP

11. Hipotesis Dukungan Internal : Hasil menunjukan bahwa ada dampak antara dukungan internal terhadap keberhasilan/kegagalan pada implementasi SAP

12. Hipotesis Partisipasi Sistem : Hasil menunjukan bahwa ada dampak antara partisipasi sistem terhadap keberhasilan/kegagalan pada implementasi SAP

13. Hipotesis Norma Subyektivitas : Hasil menunjukan bahwa ada dampak antara norma subyektivitas keberhasilan/kegagalan pada implementasi SAP

14. Hipotesis Kemudahan Penggunaan : Hasil menunjukan bahwa ada dampak antara kemudahan penggunaan terhadap keberhasilan/kegagalan pada implementasi SAP

15. Hipotesis Norma Subyektivitas Terhadap Niat Penggunaan : Hasil menunjukan bahwa ada dampak antara norma subyektivitas terhadap niat penggunaan selama implementasi SAP 
16. Hipotesis Anggapan Manfaat Sistem Terhadap Niat penggunaan sistem : Hasil menunjukan bahwa ada dampak antara anggapan manfaat sistem terhadap niat penggunaan selama implementasi SAP

\section{AnAlisa Struktur Equation Models (SEM)}

18. Penelitian ini juga diuji menggunakan pendekatan Structure Equation Models (SEM). Hasil SEM dapat dibandingkan dengan uji model regresi. SEM juga menguji keseluruhan variabel yang telah dilakukan pada uji regresi. Pengujian menggunakan model diagram path dengan estimasi hasil sebagaimana gambar dibawah :

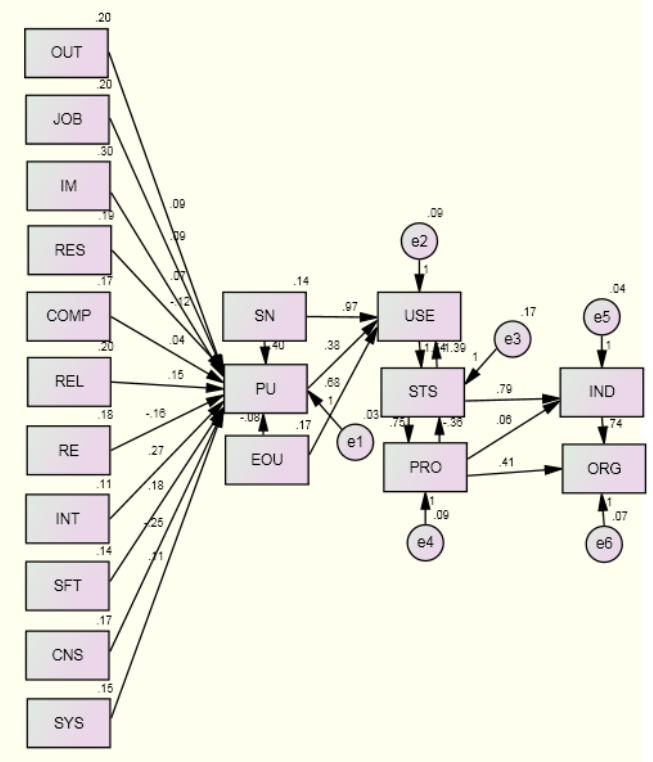

19.

\section{KESIMPULAN}

21. Berdasar penelitian diatas, yang telah dilakukan dengan uji regresi dan SEM menggunakan pendekatan teori TAM, kerangka kerja DM dan PMBOK maka dapat disimpulkan :

22. Hampir seluruh variabel yang diuji menunjukan bahwa ada dampak positif terhadap keberhasilan/kegagalan implementasi SAP pada industri retail di Indonesia.

23Hanya dua variabel menunjukan hasil dampak negatif (realibilitas sistem dan faktor keberhasilan implementasi proyek menggunakan SAP ASAP) yang berdampak terhadap keberhasilan/kegagalan implementasi SAP di industri retail di Indonesia

http://ejournal.urindo.ac.id/index.php/TI

\section{DAFTAR PUSTAKA}

[1] Blerta Abazi Chauzi and Zamir Dika, "Critical Success Factors in ERP Implementation" "Academic Journal of Business, Administration, Law, and Social Siceinces, IIPCCLPublishing, vol. 2 no.3, pp. 19-20, November 2016.Vidyaranya B Gargeya, "Success and failure factors of adopting SAP in ERP System implementation", Business Process Management Journal, vol .11 No.5, 2017, Emerald group publishing limited, pp,2.SAP is Retail Solution portfolio, "Deliver game-changing experiençes with insight into behaviour and demand" , www.sap.com, accessed march, 2019.

[2] PMl Oragnisation, "What is Project Management , www.pmi.org, accessed march 2019.

[3] Kaveh Mohammad Cyrusland et.all, "The critical success factors across ASAP methodology in ERP Implementation ", CIE42 Proceeding, 16-18 July 2012, Capetown, South Africa.

[4] Kung Tech Wong et.all. " Understanding Studetns Tearchers behaviour intention to use technology : TAM validation and Testing ", International Journal of Instruction, January 2013, Vol 6.No.1.

[5] Kumar Vinod.et all (2012). An Investigation of Critical Management Issues in SAP Implementation : Empirical Evidence from Canadian Organizations.Carleton University.Ottawa Ontario, Canada.

[6] Moohebat, Reza (2010). A Comparative Study of Critical Success Factors (CSF's) in Implementation of SAP in Developed and Developing Countries. Dept. Of MIT. University of Payam-e. Iran.

[7] Parr ,Ann (2012). A Taxonomy of SAP Implementation Approach. School of Bussiness System, Monash University, Clayton Victoria, Australia.

[8] Sumner, Mary (2013). Risk Factor in Enterprisewide/SAP Project. School of Business, Southern Illinois University, USA.

[9] Chung, Boo Young (2014). An Analysis of success and failure factors for SAP systems in Engineering and Construction Firms. Dissertation Faculty of the Graduate Schoolof the University of Maryland, College Park.

[10] Linthicum David.S (2014). Enterprise Application Integration, Canada, Addison Wesley Information Technology Series.

[11] J.Becker,W.Uhr, O.Vering (2001). Retail Informatin System Based on SAP Product, Springer-Verlag, Berlin, Heilderberg

[12] Leon Alexis (2000). ERP Demystified, Tata McGrawhill PublishingCo.Ltd, New Delhi

[13] Bhagwani, Anil (2009), Critical Success Factors in Implementing SAP ERP Software, University of Kansas.

[14] Chuttur Mohammad (2009), Overview of the Technology acceptance Model: Origins, Developments, and Future Directions, Indiana University, USÁ

[15] DeLone William $\mathrm{H}$ and McLean Ephraim R, The Delone and McLean Model of Information Systems 
Success: A Ten Year Update, Journal of Management Information System/Spring 2003, Vol .19 No.4 , 2003

[16] Laney Dale (2006). SAP R/3 Security for IT Auditors and Managers.California.

[17] Linthicum David.S (2000). Enterprise Application Integration, Canada, Addison Wesley Information Technology Series.

[18] J.Becker,W.Uhr, O.Vering (2001). Retail Informatin System Based on SAP Product, Springer-Verlag, Berlin, Heilderberg

[19] Leon Alexis (2000). ERP Demystified, Tata McGrawhill PublishingCo.Ltd, New Delhi

[20] Bhagwani, Anil (2009), Critical Success Factors in Implementing SAP ERP Software, University of Kansas.

[21] Chuttur Mohammad (2009), Overview of the Technology acceptance Model : Origins,
Developments, and Future Directions, Indiana University, USA

[22] DeLone William $\mathrm{H}$ and McLean Ephraim R, The Delone and McLean Model of Information Systems Success: A Ten Year Update, Journal of Management Information System/Spring 2003, Vol .19 No.4 , 2003, Lynn Silipigni Connaway and Ronald R' Powell, Basic research methods for librarians, Greenwood publishing group, Santa Barbara, California, 2007 